\title{
Return of the walking dead: First verified record of the shrew Crocidura leucodon (Hermann, 1780) in Hamburg, Germany
}

\author{
Robert Klesser ${ }^{1,2}$, Frederik Jessen ${ }^{2}$, Jörgen Ringenberg ${ }^{3}$, Matthias Preu $\beta^{2}$, Thomas Kaiser ${ }^{2}$, \\ Martin Husemann ${ }^{2}$ \\ 1 Naturkundemuseum Leipzig, Lortzingstraße 3, D-04105 Leipzig, Germany \\ 2 Centrum für Naturkunde, Universität Hamburg, Martin-Luther-King-Platz 3, D-20146 Hamburg, Germany \\ 3 Tatenberg, D- 21037 Hamburg, Germany \\ http://zoobank.org/C34E0741-F7ED-482A-A014-082A464E571F \\ Corresponding author: Robert Klesser (robert.klesser@leipzig.de)
}

Academic editor: Alexander Haas • Received 13 April 2021 • Accepted 14 May 2021 • Published 25 May 2021

\begin{abstract}
The bicolored shrew Crocidura leucodon so far has not been reported in Hamburg with certainty. Some plausible historical records before 1920 are present; in turn, two more recent records are doubtful for different reasons. Hence, the Red List status of the species for Hamburg has to be considered uncertain (either not present, or extinct). A citizen scientist provided a specimen of an unknown shrew, an accidental catch by a snap trap, to the Centrum für Naturkunde. The specimen was caught on the $12^{\text {th }}$ of September 2019 in Tatenberg, Hamburg. It was morphologically and genetically clearly determined as C. leucodon. This find represents the first confirmed record of $C$. leucodon for the federal state of Hamburg and increases the number of shrew species recorded in Hamburg to five. The Red List status of the species will have to be reevaluated.
\end{abstract}

\section{Key Words}

Citizen Science, local extinction, Red List, rediscovery

\section{Introduction}

In Germany three genera of shrews can be found: Crocidura, Sorex, and Neomys. Within the genus Crocidura three species occur in Germany: Crocidura suaveolens (Pallas 1811), C. leucodon (Hermann 1780) and C. russula (Hermann 1780). While $C$. russula remains relatively common, the other two species are considered threatened, as they are adapted to agriculturally extensively used habitats. Although no native German shrew is a relevant species for the European Commission Habitats Directive (92/43/EEC), all shrew species in Germany are legally protected by the Bundesartenschutzverordnung (BArtSchV); but in the current Red List for the country four out of the five shrew species are considered least-concern species (Meinig et al. 2020). Crocidura leucodon's Red List status in Germany was NT in 2020 (Near Threatened, German Red List "V").
Generally, all shrew species are more common in the southern and eastern parts of Germany with their density declining to the north. While Crocidura suaveolens is not found in northern Germany at all, the distribution of C. leucodon reaches the federal state Schleswig-Holstein. However, especially in the northern parts of the distribution, it occurs only scattered. In Schleswig-Holstein, the species is listed as vulnerable (Borkenhagen 2014); similarly, the species was listed as vulnerable in Lower Saxony and Bremen in 1991 (Heckenroth 1993; Meinig et al. 2020); in Hamburg, the species was even considered extinct (Fig. 1, Schäfers et al. 2016). However, so far no secure records of the bicolored shrew are available for Hamburg (Ebersbach 2015; Schäfers et al. 2016), suggesting the species may have never been present. Here, we report the first confirmed record of C. leucodon for Hamburg. 


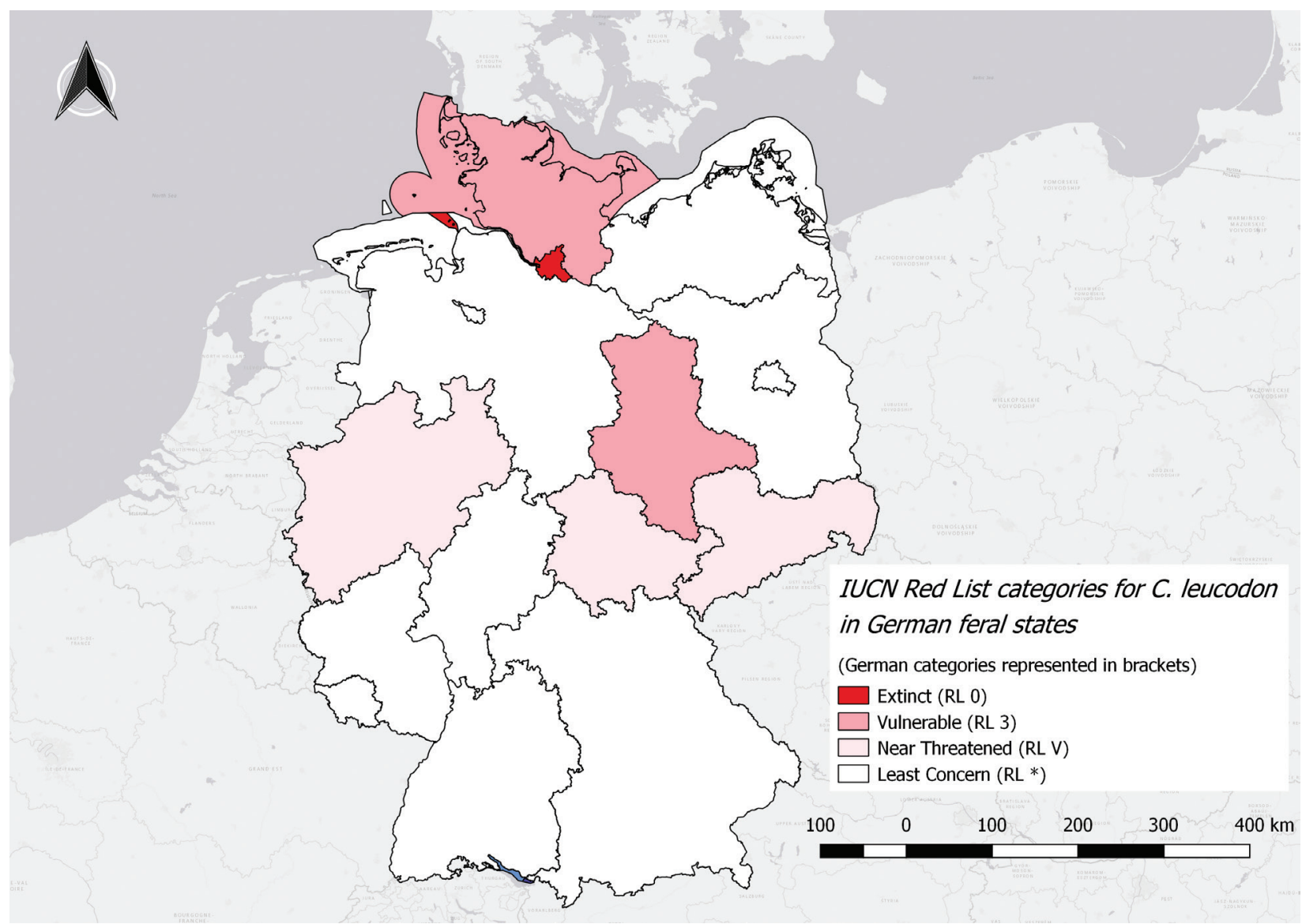

Figure 1. Map of Red List categories of C. leucodon in the German federal states based on Meinig et al. (2020). The city federal state Bremen is included in Lower Saxony and has no separate Red List. All Red List categories were taken from the German Red List of mammals (Meinig et al. 2020), which includes an overview of all federal states.

\section{Material and methods}

Two potential specimens of Crocidura leucodon were donated to the Zoological Museum Hamburg. Specimen ZMH-T-3022 was caught in a snap trap on 09.12.2019 in a private barn in south eastern Hamburg $\left(53^{\circ} 30^{\prime} 00.0^{\prime \prime} \mathrm{N}\right.$, $10^{\circ} 04^{\prime} 48.0^{\prime \prime E}$; see Fig. 2). The juvenile individual ZMH-T-3023 was found gasping on 12.07.2016 on a northern Hamburg private garden plot $\left(53^{\circ} 34^{\prime} 48.0^{\prime \prime} \mathrm{N}\right.$, $9^{\circ} 48^{\prime} 36.0^{\prime \prime} \mathrm{E}$ ), died shortly after and was subsequently donated to the CeNak collection. Both specimens were conserved in $70 \%$ ethanol.

Morphological identification was performed following the keys and descriptions implemented in Krapp (1990), Angermann (2012) and Schaefer (2009). In order to provide images of skeletal characters relevant for identification, micro-computed tomography $(\mu \mathrm{CT})$ scans of the skull and thorax were performed with an YXLON FF20 CT (Yxlon International GmbH, Hamburg). We used the micro-focus setting with the following parameters: $80 \mathrm{kV}$, $40 \mathrm{~mA}$, no filter, pixel size of $45.4 \mu \mathrm{m}$. Images were reconstructed using CERA (Siemens Healthcare $\mathrm{GmbH}$, Erlangen) and processed using VGSTUDIO MAX (Volume Graphics, Heidelberg).

To verify the morphological diagnosis, we performed DNA barcoding. Total genomic DNA was extracted of a piece of tongue using a standard CTAB protocol (Borges et al. 2009). A fragment of the barcoding gene Cytochrome Oxydase I (COI) was amplified using the primers LCOJJ and HCOJJ (Astrin and Stüben 2008). PCR was performed with the following setup: $5.7 \mu \mathrm{l}$ PCR grade water, $2 \mu \mathrm{l} 5 \mathrm{x}$ buffer, $0.5 \mu \mathrm{l}$ of each primer, $0.2 \mu \mathrm{lNT}$ P's, $0.1 \mu 1$ DreamTaq polymerase and $1 \mu 1$ template. PCR conditions were as follows: activation step at $95{ }^{\circ} \mathrm{C}$ for $5 \mathrm{~min}$, followed by 35 cycles of $30 \mathrm{sec}$. denaturation at $95{ }^{\circ} \mathrm{C}, 30 \mathrm{sec}$. annealing at 48 and $1 \mathrm{~min}$ elongation at $72^{\circ} \mathrm{C}$. Cycling was terminated by a final extension step at $72^{\circ} \mathrm{C}$ for $10 \mathrm{~min}$. PCR success was checked by gel electrophoresis and successful products were purified with an enzyme mix consisting of Exonuclease I and Shrimp-Alkaline Phosphatase (ExoSap). Amplicons were sent to Macrogen (Amsterdam, Netherlands) for sequencing.

The resulting chromatogram was checked, trimmed and proofread in Geneious v. 9 (Kearse et al. 2012). In a first step, we searched the cleaned sequence in NCBI BLAST (Geer et al. 2009), GBOL (Geiger et al. 2016) and BOLD (Ratnasingham and Hebert 2007) to confirm the determination of the specimen as Crocidura leucodon. Secondly, we reconstructed a phylogenetic tree including the different species of the genus native to Germany to see the phylogenetic position of our specimen to confirm the morphological identification. Several sequences of Sorex minutus, 


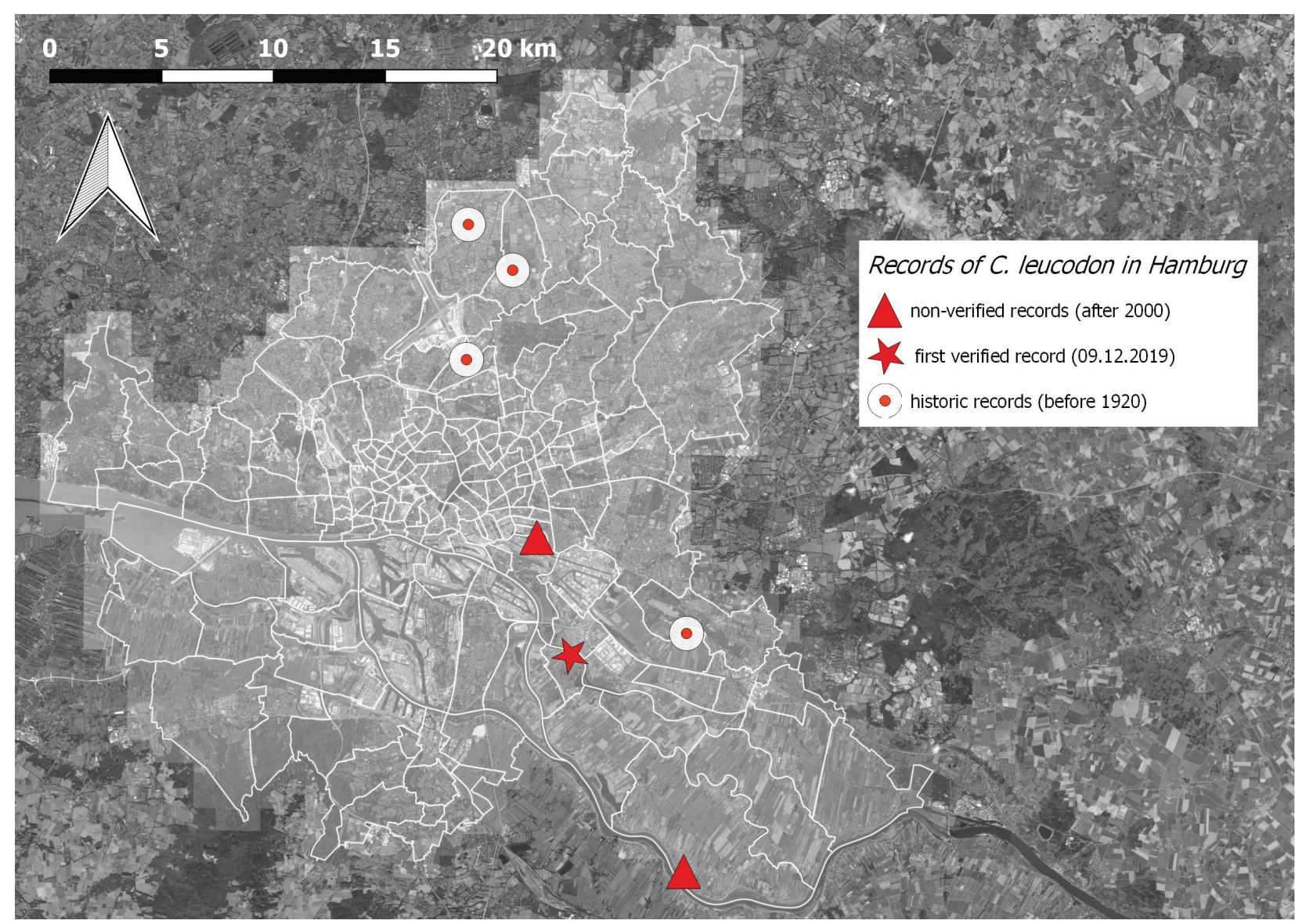

Figure 2. Records of C. leucodon in Hamburg. Historic records (red dot) before 1920 are surrounded by a buffer zone as location data is not precise. Not verified records (red triangle) are doubtful, because of the lack of vouchers and unsecure identification. The only verified recent record (red star) is discussed in this paper.

Sorex araneus, Neomys anomalus, Neomys fodiens, Crocidura suaveolens, Crocidura russula and C. leucodon from both databases were downloaded and added to the dataset (Appendix 1: Table S1). MUSCLE (Edgar 2004), as implemented in Geneious was used to align all sequences. The resulting alignment was trimmed to similar length at $541 \mathrm{bp}$. The best substitution model was determined using the R package PHANGORN (Schliep et al. 2017) in mRAN v. 3.4 (Microsoft 2017) with RStudio v. 1.0.143 (Studio 2012). GTR was determined as best model. We generated a phylogenetic tree using RAxML-HPC2 (Stamatakis 2014) on XSEDE via Cipres Science Gateway (https://www.phylo.org/www.phylo.org).

All potential records of the bicolored shrew from Hamburg were plotted on a map (Fig. 2). Besides of the new record reported here, we included all historic and recent location data for Crocidura leucodon provided by the lower nature conservation authority in Hamburg (BUKEA). All plane-table sheet (TK25) locations were translated into coordinates by using the midpoints of the plane squares as GPS points. All coordinates were plotted on a map using QGis 2.18 (QGIS Development Team 2016); an ESRI satellite map (https://server.arcgisonline. com/ArcGIS/rest/services/World_Imagery/MapServer/ tile $/ \% 7 \mathrm{Bz} \% 7 \mathrm{D} / \% 7 \mathrm{By} \% 7 \mathrm{D} / \% 7 \mathrm{Bx} \% 7 \mathrm{D} \& \mathrm{zmax}=20 \& \mathrm{z}-$ $\mathrm{min}=0$ ) map from QGis QickMapsServices 0.9.11.1 served as base map together with a layer of the city (free licence, Freie und Hansestadt Hamburg, Landesbetrieb Geoinformation und Vermessung 2016).

The current Red List categories for all federal states were derived from the German national Red List for mammals (Meinig et al. 2020) and plotted on a second map using an ESRI Gray light layer (http://services.arcgisonline. com/ArcGIS/rest/services/Canvas/World_Light_Gray Base/MapServer/tile/ $\{\mathrm{z}\} /\{\mathrm{y}\} /\{\mathrm{x}\})$ and VG250 LAN layer for federal states from open governmental database (http:// www.bkg.bund.de, GeoBasis-DE / BKG 2021).

\section{Results}

\section{Morphological identification}

All teeth of ZMH-T-3022 are of white color (Fig. 3) leading to the genus Crocidura in Germany. The sharp delimitation of dorsal and ventral fur coloration, which is a character of Crocidura leucodon, is clearly visible in dry condition of the voucher (in ethanol this is less clearly visible). In addition, the body size of $6.5 \mathrm{~cm}$, the tail length of $3.2 \mathrm{~cm}$ and the hind foot length of $10.27 \mathrm{~mm}$ support the determination. This leads to a body length / tail length ratio of about 1:2, which is typical for C. leucodon (Krapp, 1990). The 

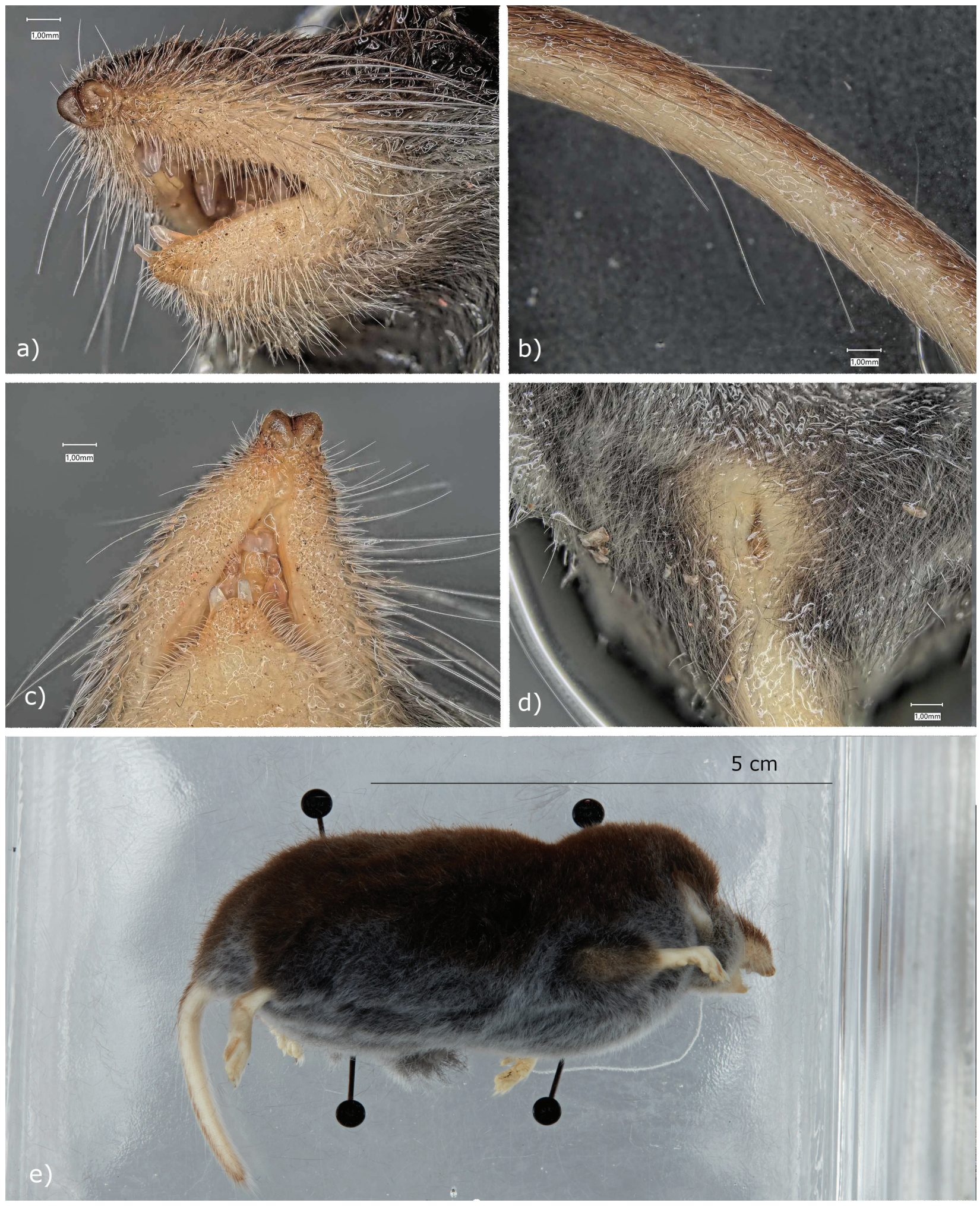

Figure 3. Macroscopic focus stacked images of the C. leucodon voucher ZMH-T-3022 from Hamburg. The genus is identified by the clearly visible white teeth (a, c), and the presence of long hair on the tail (b). The tail is bicolored with a much darker upper side. The distance between urogenital opening and excretory opening is small (female) (d); whole specimen in lateral view, the tail length is almost half of the body length (e).

micro-CT-scan revealed a bland malar bone extension of the strongly reduced zygomatic arch. The ratio of the upper edge of the maxillary alveoles and the skull height above the canines (red square) is about $1: 1$. This is a specific trait of C. leucodon (Fig 4).
For ZMH-T-3023 the general habitus supports the determination of the specimen as Crocidura russula. The dorsal and ventral fur coloration delimitation was less sharp and the tail length to body length ratio was about $1: 3$. For the reason of uncertainties in morphology-based 


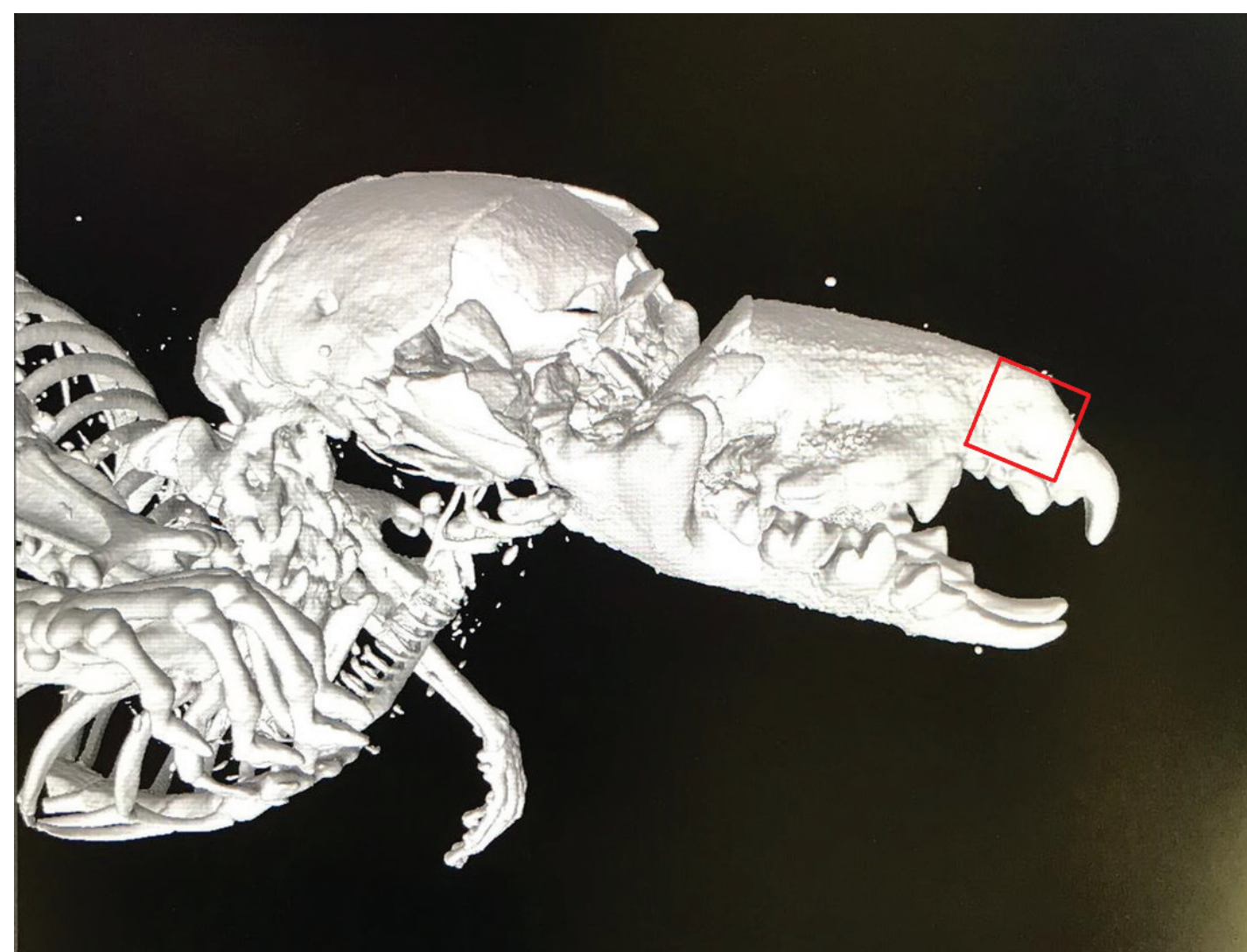

Figure 4. Micro-CT scan of the head of the specimen; the ratio of the upper edge of the alveoles in the maxilla and the skull height above the canines (red square) is about 1:1. The crack in the middle of the skull is a result of the snap trap.

determination and because the specimen is a juvenile, we rely on DNA barcoding for determination.

The DNA barcode of ZMH-T-3022 showed 99.67 $100 \%$ identical bases for Crocidura leucodon in the top five hits in BOLD (Ratnasingham \& Hebert 2007) and GBOL Geiger et al. 2016). The DNA barcode of ZMH-T-3023 showed 99.63-100\% concurrence for $C$. russula in the top five hits in both databases. The specimens each joined highly supported clades (bootstrap value $>100 \%$ ) of C. leucodon and C. russula sequences, respectively, in a phylogenetic tree of native shrew species based on COI (Fig. 5).

\section{Discussion}

Citizens of Hamburg provided two shrew specimens of unknown species assignment to the CeNak. One specimen was identified as Crocidura leucodon, the second as $C$. russula using a combination of morphological and genetic methods. While the latter is a species recently recorded (Schäfers et al. 2016), C. leucodon was considered locally "extinct" (RL category) in Hamburg, because no study undoubtedly reported the species in the state for one century.

The species was considered locally extinct (Red List 0), rather than absent in Hamburg, because of six past records for the state (Fig. 1): four before 1920, one in 2011 (Schäfers et al. 2016) and one in 2018 (database of the lower nature conservation authority of Hamburg, BUKEA Artenkataster). However, for none of these records, proper documentation exists and thus the finds cannot be confirmed and have to be regarded as doubtful.

In Hamburg, the white-toothed shrew Crocidura russula is native, but can potentially be confused with $C$. leucodon, because of a superficially similar morphology, especially when identified as living individuals (specifically juveniles) from a distance. Three of four historical records are from northern Hamburg (Itzerodt 1904, cited in Schäfers et al. 2016), where also C. russula is recorded (Schäfers et al. 2016). Only the record from eastern Hamburg before 1920 seems plausible in terms of the local habitats. This area has a lower human population density and is characterized by rather extensive agricultural land use representing typical $C$. leucodon habitat. Further, there are two additional recent records, which appear doubtful. In 2011, a pellet from a bird of prey or an owl was found in southeastern Hamburg $(53.41,10.18)$ near the Elbe, which is equivalent to the border of the federal state. The study of bones from the pellet identified C. leucodon. While in this case the identification is plausible, the original location of the specimen remains obscure. The recovery point of the pellet is less than $500 \mathrm{~m}$ away from the boarder to Lower Saxony. In this region of Lower Saxony, large scale agricultural land use provides typical habitat properties commonly associated with the demands of C. leucodon. The Elbe River represents a faunal barrier to terrestrial mammals, not so, however, to a bird 
Tree scale: 0.1

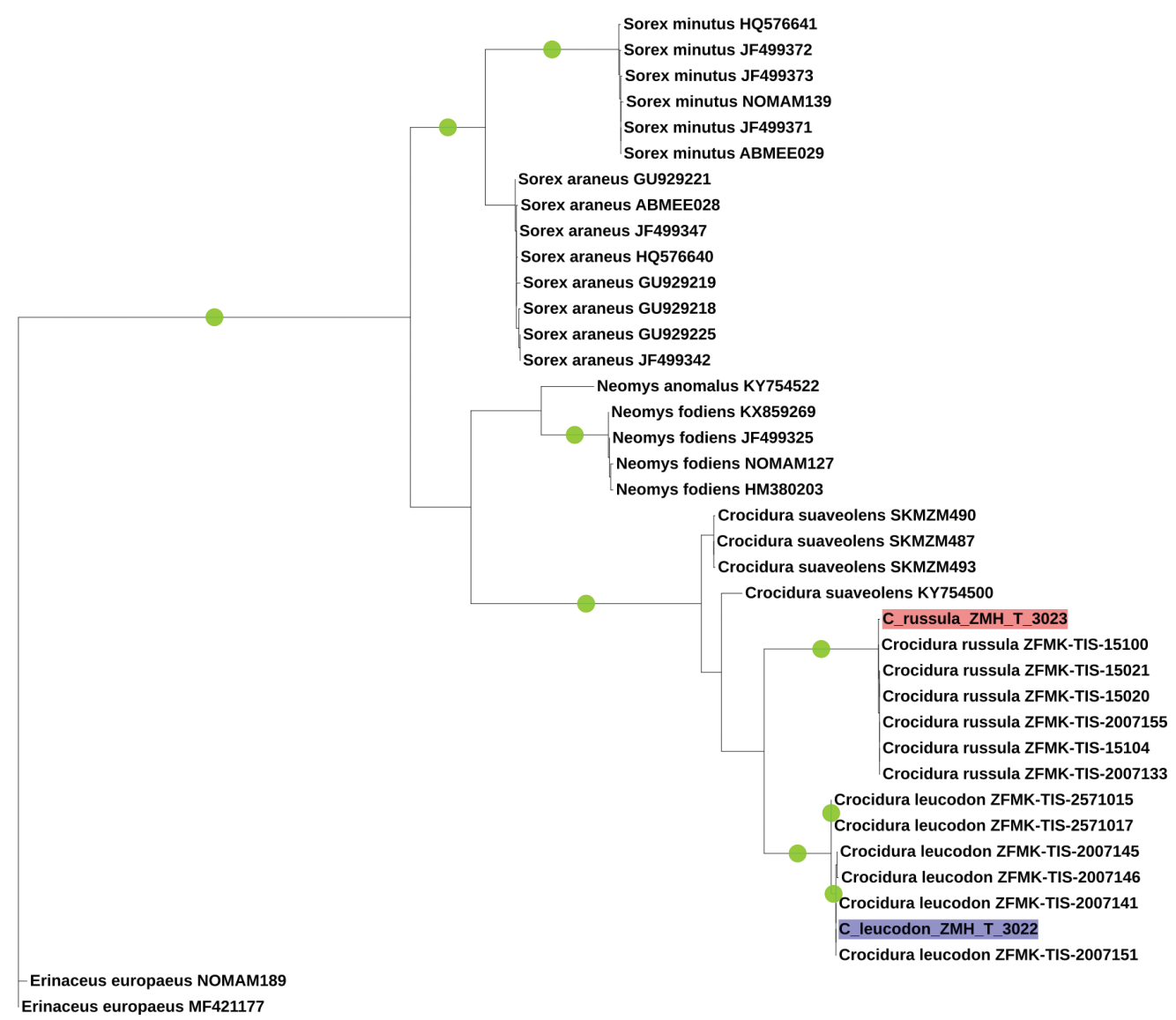

Figure 5. Phylogenetic tree (generated with RaxML) based on partial COI sequences including all native shrew species (excluding Sorex alpinus) from NCBI and BOLD (see Supplemental Table S1) and two sequences of white-toothed shrews (genus Crocidura) from Hamburg. ZMH-T-3023 clearly clusters in a clade with other $C$. russula sequences. ZMH-T-3022 falls within a clade of $C$. leucodon specimens. Green dots indicate bootstrap values $>95 \%$

of prey. A bird may thus have carried its prey from Lower Saxony into Hamburg, and hence, the record cannot securely be attributed to any federal state. In 2018, someone reported the sighting of seven individuals of $C$. leucodon at Billerhuder Island, a residential area surrounded by waterways. The settlement structure consists of houses with gardens, which potentially could provide a winter habitat. However, this island is far away from any extensively used areas covered with hedges and shrubbery (the typical habitat of C. leucodon) and hence it is difficult to explain, how a population of $C$. leucodon may have established here. Future live trapping needs to be performed to potentially confirm this record.

None of those former records have any importance for the Red List status of Crocidura leucodon in Hamburg, because of missing vouchers or other proof. Hence, we here provide the first verified and vouchered record for the federal state of Hamburg. Indeed, it generally is difficult to evaluate the significance of a Red List of a city state such as Hamburg, which is surrounded by two federal states with much larger area and more diverse habitats, i.e. Lower Saxony and Schleswig-Holstein. Nevertheless, our finding represents an important record of a small and relatively rare mammal in the vicinity of a metropole region and hence may contribute to the understanding of urban wildlife. Further, our study will aid to better evaluate the Red List status for the bicolored shrew in Hamburg; the status as extinct will have to be revoked and the species has to be re-evaluated and may have to be considered threatened by extinction. Finally, our study shows, once again, the importance of interested citizen scientists for our understanding of the distributions of species, (not only) in the urban context.

\section{Acknowledgement}

We thank Dr. Stephanie Köhnk (CeNak) for help with micro-CT imaging and Thure Dalsgaard (CeNak) for generating stacked images of the specimen. 


\section{References}

Angermann R (2012) Mammals. In: Senglaub K, Klausnitzer B, Hannemann H-J (Eds) Stresemann - Exkursionsfauna von Deutschland. Band 3: Wirbeltiere (12 ${ }^{\text {th }}$ ed.). Springer Spektrum. Heidelberg.

Astrin JJ, Stüben PE (2008) Phylogeny in cryptic weevils: molecules, morphology and new genera of western Palaearctic Cryptorhynchinae (Coleoptera:Curculionidae). Invertebrate Systematics 22(5): 503. https://doi.org/10.1071/IS07057

Borges A, Rosa MS, Recchia GH, Queiroz-Silva JR de, Bressan E de A, Veasey EA (2009) CTAB methods for DNA extraction of sweetpotato for microsatellite analysis. Scientia Agricola 66(4): 529-534. https://doi.org/10.1590/S0103-90162009000400015

Borkenhagen P (2014) Rote Liste Die Säugetiere Schleswig-Holsteins ( $4^{\text {th }}$ edn). Ministerium für Energiewende, Landwirtschaft, Umwelt und ländliche Räume des Landes Schleswig-Holstein (MELUR). www.llur.schleswig-holstein.de

Ebersbach, H. (2015): Gutachten Säugetiere (Nagetiere und Insektenfresser) für den zu erstellenden „Atlas der Säugetiere Hamburgs“, Rote Liste, Bestand und Schutz .- Authority of Stadtentwicklung und Umwelt, Department Naturschutz, unpublished.

Edgar RC (2004) MUSCLE: Multiple sequence alignment with high accuracy and high throughput. Nucleic Acids Research 32(5): 17921797. https://doi.org/10.1093/nar/gkh340

Geer LY, Marchler-Bauer A, Geer RC, Han L, He J, He S, Liu C, Shi W, Bryant SH (2009) The NCBI BioSystems database. Nucleic Acids Research, 38(SUPPL.1): 492-496. https://doi.org/10.1093/nar/gkp858

Geiger MF, Astrin JJ, Borsch T, Burkhardt U, Grobe P, Hand R, Hausmann A, Hohberg K, Krogmann L, Lutz M, Monje C, Misof B, Morinière J, Müller K, Pietsch S, Quandt D, Rulik B, Scholler M, Traunspurger W, Haszprunar G, Wägele W (2016) How to tackle the molecular species inventory for an industrialized nation-lessons from the first phase of the German Barcode of Life initiative GBOL (2012-2015). Genome 59(9): 661-670. https://doi.org/10.1139/gen-2015-0185

Heckenroth H (1993) Rote Liste der in Niedersachsen und Bremen gefährdeten Säugetierarten. Informationsdienst Naturschutz Niedersachsen 6: 222-226.
Kearse M, Moir R, Wilson A, Stones-Havas S, Cheung M, Sturrock S, Buxton S, Cooper A, Markowitz S, Duran C, Thierer T, Ashton B, Mentjies P, Drummond A (2012) Geneious Basic: an integrated and extendable desktop software platform for the organization and analysis of sequence data. Bioinformatics 28(12): 1647-1649. https:// doi.org/10.1093/bioinformatics/bts 199

Krapp F (1990) Crocidura leucodon Hermann, 1780 - Feldspitzmaus. In: Niethammer J, Krapp F (Eds) Handbuch der Säugetiere Europas: Insektenfresser - Insectivora, Herrentiere -Primates. Aula Verlag Wiesbaden, 465-484

Meinig HU, Boye P, Hutterer R, Dähne M (2020) Rote Liste und Gesamtartenliste der Säugetiere (Mammalia) Deutschlands. Naturschutz und Biologische Vielfalt, 170(2): 1.73.

Microsoft RCT (2017) Microsoft R Open (3.4). Microsoft. https://mran. microsoft.com/

QGIS Development Team. (2016) QGIS Geographic Information System. http://www.qgis.org/

Ratnasingham S, Hebert PDN (2007) BOLD: The barcode of life data system (www. barcodinglife. org). Molecular Ecology Notes 7: 355364. https://doi.org/10.1111/j.1471-8286.2007.01678.x

Schaefer M [Ed.] (2018) Brohmer-Fauna von Deutschland: Ein Bestimmungsbuch unserer heimischen Tierwelt. Quelle \& Meyer Verlag, Wiebelsheim, $832 \mathrm{pp}$.

Schäfers G, Ebersbach H, Reimers H, Landwehr F, Borggräfe K, Körber P, Janke K (2016) Atlas der Säugetiere Hamburgs: Artenbestand, Verbreitung, Rote Liste, Gefährdung und Schutz. Freie und Hansestadt Hamburg.

Schliep K, Potts AJ, Morrison DA, Grimm GW (2017) Intertwining phylogenetic trees and networks. Methods in Ecology and Evolution 8(10): 1212-1220. https://doi.org/10.1111/2041-210X.12760

Stamatakis A (2014) RAxML version 8: A tool for phylogenetic analysis and post-analysis of large phylogenies. Bioinformatics 30(9): 1312-1313. https://doi.org/10.1093/bioinformatics/btu033

Studio R (2012) RStudio: integrated development environment for R. RStudio Inc, Boston, Massachusetts. 


\section{Appendix 1}

Table S1. List of sequences from derived from GBOL, NCBI and BOLD databases providing the name of the taxon, the sequence ID and the source of the sequence.

\begin{tabular}{|c|c|c|c|}
\hline Name of species & Sequence_ID & Source & Trimmed length \\
\hline \multirow[t]{6}{*}{ Crocidura leucodon } & ZFMK-TIS-2007141 & GBOL(German Barcode of Life) & 541 \\
\hline & ZFMK-TIS-2007145 & GBOL(German Barcode of Life) & 541 \\
\hline & ZFMK-TIS-2007146 & GBOL(German Barcode of Life) & 541 \\
\hline & ZFMK-TIS-2007151 & GBOL(German Barcode of Life) & 541 \\
\hline & ZFMK-TIS-2571015 & GBOL(German Barcode of Life) & 541 \\
\hline & ZFMK-TIS-2571017 & GBOL(German Barcode of Life) & 541 \\
\hline \multirow[t]{6}{*}{ Crocidura russula } & ZFMK-TIS-15020 & GBOL(German Barcode of Life) & 541 \\
\hline & ZFMK-TIS-15021 & GBOL(German Barcode of Life) & 541 \\
\hline & ZFMK-TIS-15100 & GBOL(German Barcode of Life) & 541 \\
\hline & ZFMK-TIS-15104 & GBOL(German Barcode of Life) & 541 \\
\hline & ZFMK-TIS-2007133 & GBOL(German Barcode of Life) & 541 \\
\hline & ZFMK-TIS-2007155 & GBOL(German Barcode of Life) & 541 \\
\hline \multirow[t]{4}{*}{ Crocidura suaveolens } & KY754500 & $\operatorname{NCBI}($ GenBank $)$ & 541 \\
\hline & BOLD: SKMZM487 & BOLD (Barcode of Life) & 541 \\
\hline & BOLD: SKMZM488 & BOLD (Barcode of Life) & 541 \\
\hline & BOLD: SKMZM489 & BOLD (Barcode of Life) & 541 \\
\hline \multirow[t]{2}{*}{ Erinaceus europaeus } & MF421177 & NCBI(GenBank) & 541 \\
\hline & NOMAM189 & NCBI(GenBank) & 541 \\
\hline Neomys anomalus & KY754522 & NCBI(GenBank) & 541 \\
\hline \multirow[t]{4}{*}{ Neomys fodiens } & HM380203 & NCBI(GenBank) & 541 \\
\hline & JF499325 & NCBI(GenBank) & 541 \\
\hline & KX859269 & NCBI(GenBank) & 541 \\
\hline & NOMAM127 & NCBI(GenBank) & 541 \\
\hline \multirow[t]{8}{*}{ Sorex araneus } & BOLD: ABMEE028 & BOLD (Barcode of Life) & 541 \\
\hline & BOLD: GU929218 & BOLD (Barcode of Life) & 541 \\
\hline & BOLD: GU929219 & BOLD (Barcode of Life) & 541 \\
\hline & BOLD: GU929221 & BOLD (Barcode of Life) & 541 \\
\hline & BOLD: GU929225 & BOLD (Barcode of Life) & 541 \\
\hline & HQ576640 & NCBI(GenBank) & 541 \\
\hline & JF499342 & NCBI(GenBank) & 541 \\
\hline & JF499347 & NCBI(GenBank) & 541 \\
\hline \multirow[t]{6}{*}{ Sorex minutus } & BOLD: ABMEE029 & BOLD (Barcode of Life) & 541 \\
\hline & HQ576641 & NCBI(GenBank) & 541 \\
\hline & JF499371 & NCBI(GenBank) & 541 \\
\hline & JF499372 & NCBI(GenBank) & 541 \\
\hline & JF499373 & NCBI(GenBank) & 541 \\
\hline & NOMAM139 & NCBI(GenBank) & 541 \\
\hline
\end{tabular}

